\title{
Article
}

\section{New inequalities based on harmonic log-convex functions}

\author{
Imran Abbas Baloch ${ }^{1,2, *}$ and Silvestru Sever Dragomir ${ }^{3}$ \\ 1 Abdus Salam School of Mathematical Sciences, GC University, Lahore, Pakistan. \\ 2 Govt. College for Boys, Gulberg Higher Education Department, Punjab, Pakistan. \\ 3 Mathematics, College of Engineering and Science, Victoria University, Melbourne City, Australia.; \\ sever.dragomir@vu.edu.au \\ * Correspondence: iabbasbaloch@gmail.com
}

Received: 2 September 2019; Accepted: 22 December 2019; Published: 31 December 2019.

Abstract: Harmonic convexity is very important new class of non-convex functions, it gained prominence in the Theory of Inequalities and Applications as well as in the rest of Mathematics's branches. The harmonic convexity of a function is the basis for many inequalities in mathematics. Furthermore, harmonic convexity provides an analytic tool to estimate several known definite integrals like $\int_{a}^{b} \frac{e^{x}}{x^{n}} d x, \int_{a}^{b} e^{x^{2}} d x, \int_{a}^{b} \frac{\sin x}{x^{n}} d x$ and $\int_{a}^{b} \frac{\cos x}{x^{n}} d x \forall n \in \mathbb{N}$, where $a, b \in(0, \infty)$. In this article, some un-weighted inequalities of Hermite-Hadamard type for harmonic log-convex functions defined on real intervals are given.

Keywords: Harmonic convex functions, Hermite-Hadamard type inequalities, integral inequalities, harmonic log-convex functions.

MSC: 35B40, 35B41, 35B45, 35L05, 35R60, 58J37.

\section{Introduction}

uring the investigation of convexity, many researchers founded new classes of functions which are not convex in general. Some of them are the so called harmonic convex functions [1], harmonic $(\alpha, m)$-convex functions [2], harmonic $(s, m)$-convex functions [3,4] and harmonic $(p,(s, m))$-convex functions [5]. For a quick glance on importance of these classes and applications, see [1-19] and references therein.

Definition 1. A function $f: I \subseteq \mathbb{R} \backslash\{0\} \rightarrow \mathbb{R}$ is said to be harmonic convex function on $I$ if

$$
f\left(\frac{x y}{t x+(1-t) y}\right) \leq t f(y)+(1-t) f(x)
$$

holds for all $x, y \in I$ and $t \in[0,1]$. If the inequality is reversed, then $f$ is said to be harmonic concave.

In [5,20], Baloch et al. and Noor et al. also gave the definition of harmonic log-convex functions as follow:

Definition 2. A function $f: I \subseteq \mathbb{R} \backslash\{0\} \rightarrow(0, \infty)$ is said to be harmonic log-convex function on $I$ if

$$
f\left(\frac{x y}{t x+(1-t) y}\right) \leq[f(x)]^{1-t}[f(y)]^{t}
$$

holds for all $x, y \in I$ and $t \in[0,1]$. If the inequality is reversed, then $f$ is said to be harmonic log-concave.

In [20], Noor et al. proved the following result for harmonic log-convex functions:

Theorem 3. Let $I \subseteq \mathbb{R} \backslash\{0\}$ be an interval. If $f: I \rightarrow(0, \infty)$ is harmonic convex function, then

$$
f\left(\frac{2 a b}{a+b}\right) \leq \exp \left[\frac{a b}{b-a} \int_{a}^{b} \log \left(\frac{f(x)}{x^{2}}\right) d x\right] \leq \sqrt{f(a) f(b)}
$$


for all $a, b \in I$ and $a<b$.

Here, motivated by the above result we study the class of harmonic log-convex functions and present some new inequalities for this class of functions.

\section{Main Results}

The following result holds.

Theorem 4. Let $f: I \subseteq \mathbb{R} \backslash\{0\} \rightarrow(0, \infty)$ be harmonic log-convex function. Then, for every $t \in[0,1]$, we have

$$
\begin{aligned}
\int_{a}^{b} f(x) d x & \geq \int_{a}^{b}[f(x)]^{1-t}\left[\frac{a^{2} b^{2}}{[(a+b) x-a b]^{2}} f\left(\frac{a b x}{(a+b) x-a b}\right)\right]^{t} d x \\
& \geq \begin{cases}(1-2 t) a^{2} b^{2} \int_{\frac{a b}{(1-t) a+t b}}^{\frac{a b}{(a+1-t) b}} \frac{[(a+b) t u-a b]^{2(t-1)}}{[a b-(1-t)(a+b) u]^{2 t}} f(u) d u & \text { if } t \neq \frac{1}{2} \\
\frac{2 a b}{a+b} \ln \left(\frac{b}{a}\right) f\left(\frac{2 a b}{a+b}\right) & \text { if } t=\frac{1}{2} .\end{cases}
\end{aligned}
$$

Proof. The cases $t=0, \frac{1}{2}, 1$ are obvious. Assume that $t \in(0,1) \backslash\left\{\frac{1}{2}\right\}$. By the harmonic log-convexity of $f$ we have

$$
[f(x)]^{1-t}\left[f\left(\frac{a b x}{(a+b) x-a b}\right)\right]^{t} \geq f\left(\frac{\frac{a b x^{2}}{(a+b) x-a b}}{t x+(1-t) \frac{a b x}{(a+b) x-a b}}\right) f\left(\frac{a b x}{(a+b) t x-(2 t-1) a b}\right)
$$

for any $x \in[a, b]$. This allows that

$$
[f(x)]^{1-t}\left[\frac{a^{2} b^{2}}{[(a+b) x-a b]^{2}} f\left(\frac{a b x}{(a+b) x-a b}\right)\right]^{t} \geq \frac{a^{2 t} b^{2 t}}{[(a+b) x-a b]^{2 t}} f\left(\frac{a b x}{(a+b) t x-(2 t-1) a b}\right) .
$$

Integrating the inequality (6) over $x$ on $[a, b]$, we have

$$
\int_{a}^{b}[f(x)]^{1-t}\left[\frac{a^{2} b^{2}}{[(a+b) x-a b]^{2}} f\left(\frac{a b x}{(a+b) x-a b}\right)\right]^{t} d x \geq \int_{a}^{b} \frac{a^{2 t} b^{2 t}}{[(a+b) x-a b]^{2 t}} f\left(\frac{a b x}{(a+b) t x-(2 t-1) a b}\right) d x .
$$

Since $t \neq \frac{1}{2}$, then $u=\frac{a b x}{(a+b) t x-(2 t-1) a b}$ is the change of variable with $d x=\frac{(1-2 t) a^{2} b^{2}}{[(a+b) t u-a b]^{2}} d u$. For $x=a$, we get $u=\frac{a b}{t a+(1-t) b}$ and for $x=b$, we get $u=\frac{a b}{(1-t) a+t b}$. Therefore,

$$
\int_{a}^{b} \frac{a^{2 t} b^{2 t}}{[(a+b) x-a b]^{2 t}} f\left(\frac{a b x}{(a+b) t x-(2 t-1) a b}\right) d x=(1-2 t) a^{2} b^{2} \int_{\frac{a b}{t a+(1-t) b}}^{\frac{a b}{(1-t) a+t b}} \frac{[(a+b) t u-a b]^{2(t-1)}}{[a b-(1-t)(a+b) u]^{2 t}} f(u) d u,
$$

and hence the second inequality (4) is proved. By the Hölder integral inequality for $p=\frac{1}{1-t}, q=\frac{1}{t}$, we have

$$
\begin{aligned}
& \int_{a}^{b}[f(x)]^{1-t}\left[\frac{a^{2} b^{2}}{[(a+b) x-a b]^{2}} f\left(\frac{a b x}{(a+b) x-a b}\right)\right]^{t} d x \\
& \leq\left(\int_{a}^{b}\left([f(x)]^{1-t}\right)^{\frac{1}{1-t}} d x\right)^{1-t}\left(\int_{a}^{b}\left(\left[\frac{a^{2} b^{2}}{[(a+b) x-a b]^{2}} f\left(\frac{a b x}{(a+b) x-a b}\right)\right]^{t}\right)^{\frac{1}{t}} d x\right)^{t} \\
& =\left(\int_{a}^{b} f(x) d x\right)^{1-t}\left(\int_{a}^{b} \frac{a^{2} b^{2}}{[(a+b) x-a b]^{2}} f\left(\frac{a b x}{(a+b) x-a b}\right) d x\right)^{t} \\
& =\left(\int_{a}^{b} f(x) d x\right)^{1-t}\left(\int_{a}^{b} f(x) d x\right)^{t}=\int_{a}^{b} f(x) d x
\end{aligned}
$$

This proves the first part of inequality (4). 
Author Contributions: All authors contributed equally to the writing of this paper. All authors read and approved the final manuscript.

Conflicts of Interest: "The authors declare no conflict of interest."

\section{References}

[1] İşcan, İ. (2014). Hermite-Hadamard type inequaities for harmonically convex functions. Hacettepe Journal of Mathematics and Statistic 43 (6), 935-942.

[2] İşcan, İ. (2016). Hermite-Hadamard type inequalities for harmonically $(\alpha, m)$-convex functions. Hacettepe Journal of Mathematics and Statistics, 45(2), 381-390.

[3] Baloch, I. A., İşcan, İ., \& Dragomir, S. S. (2016). Fejer type inequalities for harmonically $(s, m)$-convex functions. International Journal of Analysis and Applications, 12(2), 188-197.

[4] Baloch, I. A., \& İşcan, İ. (2016). New Hermite-Hadamard and Simpson type inequalities for harmonically $(s, m)$-convex functions in Second Sense. International Journal of Analysis, Article ID 672675.

[5] Baloch, I. A., \& İşcan, İ. (2017). Some Hermite-Hadamard type integral inequalities for harmonically $(p,(s, m))$-convex functions. Journal of Inequalities $\mathcal{E}$ Special Functions, 8(4), 65-84.

[6] Dragomir, S. S., Pečarić, J., \& Persson, L. E. (1995). Some inequalities of Hadamard type. Soochow Journal of Mathematics, 21(3), 335-341.

[7] Dragomir, S. S. (2015). Inequalities of Jensen type for HA-convex functions. Fasciculi Mathematici, 55(1), 35-52.

[8] Dragomir, S. S. (2006). Bounds for the normalised Jensen functional. Bulletin of the Australian Mathematical Society, 74(3), 471-478.

[9] Dragomir, S. S., Pečarić, J., \& Persson, L. E. (1995). Properties of some functionals related to Jensen's inequality. Acta Mathematica Hungarica, 69(4), 129-143.

[10] Fang, Z. B., \& Shi, R. (2014). On the $(p, h)$-convex function and some integral inequalities. Journal of Inequalities and Applications, 2014(1), 45.

[11] Hazy, A. (2011). Bernstein-Doetsch-type results for $h$-convex functions. Mathematical Inequalities E Applications, 14(3), 499-508.

[12] Jensen, J. L. W. V. (1906). Sur les fonctions convexes et ingalits entre les valeurs moyemes. Acta Mathematica 30, 175-193.

[13] Mercer, A. M. (2003). A variant of Jensen's inequality. Journal of Inequalities in Pure and Applied Mathematics , 4(4), Article ID, 73.

[14] Niculescu, C., \& Persson, L. E. (2006). Convex functions and their applications. New York: Springer.

[15] Olbrys, A. (2015). On separation by h-convex functions. Tatra Mountains Mathematical Publications, 62(1), $105-111$.

[16] Peajcariaac, J. E., \& Tong, Y. L. (1992). Convex functions, partial orderings, and statistical applications. Academic Press.

[17] Varošanec, S. (2007). On h-convexity. Journal of Mathematical Analysis and Applications, 326(1), 303-311.

[18] Agarwal, R. P., \& Dragomir, S. S. (1998). The property of supermultiplicity for some classical inequalities and applications. Computers \& Mathematics with Applications, 35(6), 105-118.

[19] Baloch, I. A., De La Sen, M., \& İşcan, İ. (2019). Characterizations of Classes of Harmonic Convex Functions and Applications. International Journal of Analysis and Applications, 17(5), 722-733.

[20] Noor, M. A. Noor., K. I., \& Awan, M. U. (2014). Some characterizations of harmonically log-convex functions. Proceeding of the Jangjeon Mathematical Society, 17(1), 51-61. 